\title{
Examining the elevated risk of COVID-19 in transgender communities with an intersectional lens
}

\author{
Peter D. Goldie ${ }^{1}$ D $\cdot$ Isha Chatterjee ${ }^{2}$
}

Received: 6 January 2021 / Accepted: 7 September 2021 / Published online: 6 October 2021

(c) The Author(s), under exclusive licence to Springer Nature Switzerland AG 2021

\begin{abstract}
COVID-19 has presented unique and unprecedented struggles for all people, yet they tend to be magnified among marginalized communities. Indeed, in the United States, transgender (trans) people experience oppression in many facets of their lives, which places them at an increased risk for both COVID-19 exposure and complications. This oppression can be broadly categorized into two distinct, yet interrelated categories: health disparities (e.g., decreased immune health) and structural barriers (e.g., employment discrimination, policing). Recent scholarship has examined trans people's risk for COVID-19 exposure and mortality, however few articles examine intersectional identities, and, to our knowledge, none have interrogated oppressive power structures (e.g., the prison industrial complex). We aim to fill these critical gaps and argue that it is imperative for cisgender people to partner with trans communities to dismantle these harmful systems, positively impacting the lives of trans individuals during the pandemic and beyond. We make several key recommendations for researchers, policymakers, healthcare workers, and allies to do so.
\end{abstract}

Keywords Transgender - Intersectionality $\cdot$ COVID-19 $\cdot$ Oppression

\section{Introduction}

The COVID-19 pandemic has drastically impacted the lives of millions across the globe. In many parts of the world (e.g., New Zealand, Australia, Taiwan, United States), COVID-related restrictions have eased through 2021 as cases continue to stabilize. Yet, since the inception of the COVID-19 pandemic, marginalized communities have faced the brunt of the consequences. For instance, the infection and mortality rates of COVID-19 are three times higher for Black relative to

Peter D. Goldie

goldiep1@montclair.edu

1 Department of Psychology, Montclair State University, Montclair, NJ, USA

2 Department of Sociology, Columbia University, New York, NY, USA 
White Americans (Yancy 2020) and death rates are higher in areas of relatively greater poverty (Finch and Hernández Finch 2020). In addition to causes associated with underlying chronic health conditions, the disproportionate impact of COVID-19 on marginalized communities can be explained by social inequities and structural factors. Indeed, marginalized people have lower income statuses on average (Kochhar and Cillufo 2018) and often do not have financial safety nets; as a result, they must work (often in-person) regardless of circumstances or safety (Kantamneni 2020), and lockdown policies, while necessary, disproportionately contribute to health inequalities for marginalized communities (Perez-Brumer and Silva-Santisteban 2020). Similarly, Lesbian, Gay, Bisexual, Transgender, and Queer (LGBTQ) people are far more likely than non-LGBTQ people to work in COVID-affected industries (e.g., as educators, in food services; Human Rights Campaign 2020) or lose their livelihoods-often experiencing homelessnesswhich similarly heightens their risk for COVID-19 exposure (Homelessness Research Institute 2020; Poteat et al. 2020). Within these groups, perhaps the most vulnerable are those who experience intersecting forms of social marginalization such as "Black and Latinx gay and bisexual men, cisgender and transgender women, injection drug users, and poor people" (Bowleg 2020, p. 917; Wesp et al. 2019).

Transgender (trans) people (i.e., those whose binary or nonbinary gender identities do not match with their sex assigned at birth; Nagata et al. 2020), especially those who are marginalized along multiple axes of oppression, are particularly likely to contract the COVID-19 virus (e.g., due to engaging in sex work or homelessness; see Perez-Brumer and Silva-Santisteban 2020; Sears et al. 2021) —and, should they contract it, receive poorer standards of healthcare if any at all (see Gonzales and Henning-Smith 2017; James et al. 2016). This is due to a variety of factors we classify into two distinct yet interlinked categories: health disparities and structural disparities.

Although recent valuable scholarship has examined LGBTQ (e.g., American Psychological Association 2020) and, specifically, trans people's increased risk for COVID-19 exposure and mortality (e.g., Poteat et al. 2020), few articles examine intersectional identities, and, to our knowledge, none have located nor interrogated oppressive power structures (e.g., the prison industrial complex) and discriminatory systems (e.g., health care). This review aims to fill these critical gaps. We first outline our theoretical orientations, then describe the ways in which health (i.e., mental, behavioral) and structural disparities (e.g., policing, incarceration) contribute to trans people's heightened risk for COVID-19 exposure and risk of complications and/or death. To conclude, we outline several applied recommendations for researchers, policymakers, healthcare workers, institutions, and allies to support trans communities through the COVID-19 pandemic and beyond, which map onto our main arguments. Critiques of violent transphobic systems, as Upadhyay (2021) describes, have been offered by various Black, Indigenous, people of color (PoC), and activist-feminist scholars, yet largely ignored in academia. We merely aim to highlight how these systems are showing up in dangerous ways for trans people at present in this pandemic. 


\section{Theoretical frameworks}

Two theoretical frameworks undergird this review. First is intersectionality theory (Crenshaw 1991), which posits that individuals' marginalized identities interlock and shape their experiences in a conceptually reconstitutive (rather than additive) manner. Thus, "intersectionality highlights how lived identities, structural systems, sites of marginalization, forms of power, and modes of resistance 'intersect' in dynamic ways" (May 2015, p. 21). Intersectionality provides an appropriate lens to analyze the risks of COVID-19 affecting trans communities as it recognizes the complexities and intricacies of social identities, and provides a comprehensive basis for analysis, distinguishing between three forms of intersectionality: structural, representational, and political (Crenshaw 1991). Engaging in scholarship on oppression without considering intersectionality is problematic as it neglects complex power dynamics and fails to consider experiences that cannot be captured within discrete categories of discrimination (e.g., sexism, racism; Collins and Bilge 2020; Crenshaw 1991). For instance, trans PoC have distinct lived experiences conditioned upon the intersections of their racial and gender identities (i.e., gendered racism) which limit their access to power and privilege (e.g., higher rates of unemployment and poverty than White trans people; James et al. 2016). It is essential to note that colonization established the transphobia that exists in the U.S. at present. White supremacy and transphobia are inextricable as is their deconstruction. While this review focuses mainly on the intersections of cissexism, racism, and classism, we consider other intersections as well.

Second, this work is informed by bioecological theory, initially proposed by Bronfenbrenner (1977), which provides a detailed framework to contextualize trans people's experiences through the COVID-19 pandemic and beyond and has guided similar previous scholarship (e.g., Becker and Todd 2018). This model allows for the systematic evaluation of both micro- and macro-level factors that shape the ways trans people experience themselves and the world and lends itself well to comprehensively understanding transphobia. Per the model, there are four levels of context. First, the microsystem refers to factors in an individual's immediate environment. In this case, individuals around trans people directly impact their safety and affirm (e.g., conveying their worth) or harm them (e.g., via microaggressions). Next, the mesosystem refers to associations between factors or individuals in one's microsystem. This includes interactions between people a trans person speaks with (e.g., a conversation between their friends and coworkers), which shape their world by changing the way these people treat them. Third, the exosystem refers to distal factors that the individual does not directly interact with or have control over. An example is a trans person's parent's church, which can affect the relationship between the parent and their child. Finally, the macrosystem refers to the most distal factors, such as culture or policies. For example, government policies, economic systems, and cultural norms that disadvantage trans people significantly shape their development (e.g., self-concept). Bioecological theory posits that relations between these systems are bidirectional. A cultural shift in trans acceptance and support, for example, will shift the way a trans person is treated by those around them; conversely, the ways in which others view 
and treat trans people play a vital role in enacting large-scale social and cultural change.

Throughout this essay, we lean on these frameworks to present a wider perspective on the ways intersecting trans identities and multiple layers of context raise the risks and impacts of COVID-19 on trans communities.

\section{Health disparities}

\section{Mental health}

Mental health has been an important part of the conversation surrounding COVID19 given the rise of mental health issues (United States Census Bureau 2020). This section focuses primarily on micro- and mesosystemic factors related to trans people's mental health outcomes in the COVID-19 era. However, we conceptualize COVID-19 as a form of mass trauma (see Hoffman and Kruczek 2011), particularly for trans people, many of whom are currently facing additional trauma both related and unrelated to this pandemic.

Trans people experience extremely high rates of mental health issues (see Massachusetts Department of Public Health 2009) due to stigma and discrimination, which foster hostile and stressful environments (Meyer 2003). In fact, trans people are more than four times as likely to struggle with depression (Witcomb et al. 2018) and twice as likely to struggle with anxiety as compared to the general population (Bouman et al. 2017). Beginning in youthhood, trans people frequently experience physical violence, bullying (Johns et al. 2019), rejection, abuse, and exclusion from their families and religious or spiritual communities (James et al. 2016), which is often psychologically harmful (see Klein and Golub 2016). Rates of mental health issues are particularly high among those who are $\mathrm{PoC}$, assigned female at birth, and lower-income (Herman et al. 2019).

Inevitably, these difficulties have continued or been exacerbated during the COVID-19 pandemic. Due to pandemic-related events (e.g., being laid off due to financial recession), many trans people may be confined to non-affirming environments (Gonzales et al. 2020), such as living with transphobic family members who invalidate their trans identity. Resulting chronic stress can negatively impact trans people's immune system function and place them at further COVID-19 risk (van der Miesen et al. 2020). Recent data indicate that, during the current pandemic, about three out of four trans people have experienced anxiety and depression respectively, and such experiences are more common among trans women than trans men, nonbinary people, and other members of the LGBTQ community (Gonzales et al. 2020; Jarrett et al. 2020). While little research has examined the impact of COVID-19 on suicide attempts, there has been a notable spike in the volume of calls to suicide prevention hotlines in recent months (Shelton 2020), including a trans-specific hotline (Newberry 2020). Mental health issues associated with gender dysphoria (i.e., distress that results from a misalignment between one's assigned sex at birth and their gender identity; American Psychiatric Association 2013) may be exacerbated by the widespread deferral of gender-affirming medical treatments due to COVID-19 
concerns (van der Miesen et al. 2020), an example of a key exosystemic or institutional factor. In fact, data suggest that gender-affirming treatments substantially improve trans individuals' mental health outcomes (Almazan and Keuroghlian 2021).

Considerably less research has focused on how mental illnesses can exacerbate one's COVID-19 symptoms, should one contract the virus. Yet it is well-documented that mental illness is linked to reduced immune health (Bennet and Molofsky 2019), which is associated with COVID-19 virus severity (CDC 2020d). Furthermore, Wang and colleagues (2020) analyzed over 61 million patients' health records and found that COVID-19 patients with a diagnosed mental disorder had substantially higher death rates. Therefore, the alarmingly high rates of mental health issues that trans people experience appear to increase their likelihood of experiencing severe COVID-19 symptoms or mortality.

\section{Behavioral health}

Many behavioral health factors similarly shape the COVID-19 landscape and outlook for trans communities, many of which exist at the individual, interpersonal, or microsystemic level. A breadth of literature indicates that trans people smoke cigarettes at far higher rates than the general population (e.g., Creamer et al. 2019). Smoking is associated with COVID-19 illness severity (Guan et al. 2020) and heightens one's risk for respiratory diseases such as asthma (US Department of Health and Human Services 2010). This, in turn, is linked to increased rates of hospitalization for those who contract the COVID-19 virus (CDC 2020e). A side effect of hormone replacement therapy (HRT), a gender affirmation medication that about half of trans people in the U.S. elect to take (James et al. 2016) is thromboembolism (i.e., blood clotting)—which is both a severe symptom of COVID-19 (Gregory 2021) and is exacerbated by smoking (Goldstein et al. 2019). This places many trans individuals at a heightened risk of severe or life-threatening effects should they contract the COVID-19 virus. Additionally, trans people often have unmet health needs, fail to receive routine care, and put off on scheduling appointments with their doctors due to fear of discrimination (Grant et al. 2011) which frequently shows up in microsystemic ways (e.g., being mistreated by medical providers). Failing to receive care can leave serious health conditions undiagnosed and could increase one's risk for COVID-19 complications or mortality should they contract the virus.

Exosystemic behavioral health factors too must be considered. Discrimination in medical care manifests in institutional policies (e.g., medical facilities that require patients to confirm and use legal/dead names rather than chosen/preferred names and the systems, such as insurance companies, that mandate this). Additionally, trans people, especially trans women, PoC, sex workers, and unemployed trans people, are at an increased risk of contracting HIV (Grant et al. 2011) perhaps largely due to employment discrimination and systematic exclusion from financially stable and lucrative career paths (see Grant et al. 2011). Nearly one in five Black trans women, for example, are living with HIV (James et al. 2016) —over forty times the national average (CDC 2020c). Living with HIV might increase one's risk for experiencing 
severe COVID-19 illness (CDC 2020e). Trans women living with HIV (relative to those not living with HIV) are far more likely to be unemployed and homeless (Poteat et al. 2020) and therefore, might be less likely to receive necessary medical care should they contract the COVID-19 virus.

\section{Structural disparities}

\section{Medical: health care and COVID-19 vaccination programs}

Numerous barriers contribute to the poor health care provided to trans communities, and these barriers are magnified for those with intersecting marginalized identities (e.g., race, gender, disability status). On an interpersonal level, health care providers tend to lack cultural competence and health care systems frequently have inaccurate health records (e.g., with trans patients' dead names; see Safer et al. 2016). In the mental health arena specifically, when care is accessible, trans people are pathologized solely for being trans as gender dysphoria is conceptualized as a psychiatric disorder (American Psychiatric Association 2013). On a more structural or macro- level, trans people (and especially trans $\mathrm{PoC}$ ) frequently live in poverty (Badgett et al. 2019; Poteat et al. 2020) and, therefore, are un- or underinsured, and nonbinary people and trans men are especially likely to lack access to counseling or mental health care (Jarrett et al. 2020). Historically, unequal systems have engendered medical mistrust among marginalized communities, especially since the powers that established these systems are responsible for substantiating and reinforcing discrimination against them (Jaiswal and Halkitis 2019). Among sexual and gender minorities, medical mistrust decreases engagement with health care (Eaton et al. 2015). This is particularly important at present given that the COVID-19 vaccine is a crucial tool in reducing and preventing community transmission, hospitalizations and deaths from the virus (see Kofman et al. 2021).

Unsurprisingly, this context has shaped the ways that queer and trans people view COVID-19 vaccines. Research suggests that medical mistrust is negatively associated with vaccine acceptance among trans people (da Silva et al. 2021). This might be especially salient for trans PoC (Black people in particular) given prevalent historical scientific racism (e.g., the Tuskegee experiment, the use of pseudoscientific craniology to claim that Black people have inferior intellectual capacities, the weaponization of IQ tests to justify racial segregation; see Guthrie 1976; Peters et al. 1955) as well as contemporary scientific racism (e.g., pervasive terminology used in scientific research stigmatizes communities of color, such as the use of the term "atrisk"; see O'Reilly 2020). Yet despite some reported trans community mistrust in the vaccine (da Silva et al. 2021), a recent survey found that trans adults are willing to be vaccinated at a higher rate than the general adult population (Human Rights Campaign and PSB Research 2021). Interestingly, for LGBTQ PoC (relative to White LGBTQ people), factors of greater concern were affordability, effectiveness, and side effects (Human Rights Campaign and PBS Insights 2021).

Importantly, medical trials fail to appropriately include trans participants (Andrasik et al. 2014). Indeed, no studies to date have examined interactions 
between COVID-19 vaccines and HRT. Finally, many LGBTQ people expressed concerns about government involvement in the vaccination approval and testing process (Human Rights Campaign and PSB Research 2021), exemplifying the community's tangible lack of trust in the political systems that are causing them harm.

\section{Financial: socioeconomic status and occupations}

It is extremely common for binary and nonbinary trans people alike to be lowincome, unemployed, and/or underemployed (Grant et al. 2011; Leppel 2016). This is due to a variety of factors related to systemic discrimination. Considering first the microsystemic level, trans people are frequently fired/lose their jobs (26\%), denied promotions (23\%), or not hired (44\%) solely due to being trans (Grant et al. 2011). Relatedly, trans individuals report transition-related employment terminations and being terminated when employers learn that they are trans (Legal Services NYC, 2016). Zooming out to structural factors, it is notable that trans people tend to be far less educated than cisgender (cis) people (Carpenter et al. 2020; Gonzales and Henning-Smith 2017), likely due to targeted harassment in educational environments (Kosciw et al. 2014), lacking stable housing, and overcriminalization (James et al. 2016; Sawyer and Wagner 2020) among other factors. Education levels are highly associated with income status (Jackson and Holzman 2020) as many fields with the most lucrative job opportunities require college degrees (e.g., nurses, physician assistants; Bureau of Labor Statistics 2020). Importantly, preliminary data suggest that COVID-related job losses and furloughs intensify poverty among trans people, and trans women and trans PoC in particular (Poteat et al. 2020; Sears et al. 2021).

Indeed, these discriminatory factors contribute to the overrepresentation of trans people, and particularly trans $\mathrm{PoC}$, in (illegal) underground economies such as sex work and drug dealing, often to survive (Grant et al. 2011; Legal Services NYC, 2016). This increases their risk of incarceration and must be considered intersectionally - there are stark racial discrepancies among those involved in this work. While $11 \%$ of trans people overall report engaging in sex work, $44 \%$ of African-American and $28 \%$ of Latino trans people report doing so (Grant et al. 2011), and trans sex workers of color are far more likely to experience criminalization given that carceral systems are rooted in racist transmisogyny (see Irvine 2014). During the COVID19 crisis, the health consequences of sex work can be particularly detrimental. Sex workers who have continued to work in person despite lockdown measures have an increased risk of exposure to COVID-19, and those who have followed social distancing measures are likely struggling financially (Poteat et al. 2020). Trans sex workers frequently lack health insurance (Aggarwal 2021), which can limit their access to treatment should they contract the COVID-19 virus.

Trans people disproportionately experience homelessness as well-over one in five trans people report not having shelter (James et al. 2016). This may be due to a lack of stable or livable income and/or the high prevalence of housing discrimination affecting trans communities (Grant et al. 2011). Homelessness is a significant risk factor for exposure to COVID-19 primarily because it renders social distancing and frequent handwashing difficult (Homelessness Research Institute 2020; Poteat 
et al. 2020). At times, trans people may obtain spots in (gender-segregated) shelter systems, although doing so may entail enduring anti-trans discrimination and make it similarly difficult to socially distance due to crowding (Poteat et al. 2020).

Not all trans people experience equal COVID-19 risk, and levels of risk are inextricably linked to financial stability and employment. While limited data exist, recent reports indicate that $40 \%$ of LGBTQ people work in industries highly affected by COVID-19 that require working in person (e.g., hospitals, food service; Human Rights Campaign 2020), increasing individuals' chances of exposure to the virus. Higher-income trans people may be more likely to have the option to work from home and avoid employment-related risk, yet those living in poverty must work to live, and likely cannot afford high-quality COVID-19 personal protective equipment (e.g., N95 masks). This further heightens their risk of contracting the virus and, as low-income status is associated with poor physical and mental health (Wang and Geng 2019), these individuals are at a further increased risk for complications and mortality should they contract it.

\section{Policing and incarceration}

While this research domain is underdeveloped (Stotzer 2014), it is evident that trans people, especially trans immigrants and trans $\mathrm{PoC}$, are disproportionately targeted by police and incarcerated in the United States (U.S.). On a microsystemic level, Lambda Legal (2015) reports that over a third of trans people have been wrongly accused of a crime, and the vast majority of trans women who interact with police officers experience hostility. Trans people are nearly three times as likely to be incarcerated than the general population, and approximately one in ten undocumented and Black trans people, respectively, are incarcerated (James et al. 2016; Sawyer and Wagner 2020). Trans women of color are incarcerated most frequently; more than one in four report spending time in jail or prison (Lambda Legal 2015). Yet the U.S. police system has little to no accountability (Chavis and Degnan 2017) and the common abuse, wrongful arrests, and violence (see Stotzer 2014) that harm trans communities remain unchecked. Trans people's work in underground economies increase their rates of incarceration; nearly all trans sex workers report having multiple interactions with the police (James et al. 2016), and trans women who are not sex workers too are commonly profiled as such (see Carpenter and Marshall 2017). As Stotzer (2014) describes, survival crimes (e.g., sex work) might partially, but not fully explain the disproportionality in arrest rates.

Incarceration is a trans issue because the justice system disproportionately targets trans people (James et al. 2016), and a COVID-19-related issue because it is directly associated with an elevated risk of exposure to the virus. Recent data suggest that individuals who are incarcerated are over five times as likely to contract the COVID19 virus than those not incarcerated (Saloner et al. 2020). As the Equal Justice Initiative (2020) notes, inmates' inability to socially distance and quarantine as needed significantly increases their risk of contracting the virus. Further, recent work indicates that prisons in some states do not provide masks to all inmates (Wildra and Hayre 2020). All people should have the ability to take precautionary measures to 
prevent contracting COVID-19, and the failure of the prison industrial complex to allow for this is dehumanizing, violent, and aligns with its punitive (rather than rehabilitative or restorative) model. The structure of prisons is informed by macrosystemic cultural norms, such as the belief that incarcerated people do not deserve human rights, including health and safety.

\section{Recommendations}

While the issues outlined above are of utmost immediate concern given the COVID19 pandemic, they also speak to trans people's experiences at large and the injustice they face. Moreover, this work is time-sensitive given the COVID-19 crisis, yet large-scale change requires collaboration across systems to dismantle those that oppress and terrorize trans communities. Next, we offer preliminary recommendations for researchers, policymakers, healthcare workers, government bodies, pharmaceutical companies, and allies of the trans community. It is imperative that these actions are carried out to foster long-term, systems-level change that humanizes, supports, and uplifts trans communities.

\section{Researchers: across disciplines, aim to center diverse trans participants in studies}

Centering trans communities in research remains rare (Carpenter et al. 2020), and doing so will increase access to information that people may not otherwise have. In fact, the majority of individuals living in the U.S. do not personally know a single trans person (Pew Research Center 2016). Researchers are well-positioned to examine and write about trans issues and push back on colonial transphobic cultural norms. Indeed, we have highlighted the importance of including trans people in medical research specifically (e.g., vaccination clinical trials) to increase their safety in the healthcare sector. It is vital to make research findings readily accessible and intelligible, including those clarifying how COVID-19 vaccines will impact trans individuals (e.g., those on HRT).

\section{Researchers: use an intersectional lens when engaging in work with and for trans communities}

This review provides clarity about how power structures shape trans individuals' experiences based on their various social identities. Examinations of trans experiences are incomplete, misrepresentative, and often harmful without intersectional foci.

\section{Policymakers: pressure police departments to create and/or implement additional accountability measures}

Methods of doing so are well-documented in existing literature (e.g., Chavis and Degnan 2017). These include, among others, using independent prosecutors (e.g., 
from neighboring districts) to avoid conflicts of interest (Simmons 2015), use of force reporting, taking civilian input into account (US Department of Justice 2001), and mandating that officers wear body cameras when on duty (Chavis and Degnan 2017). Increasing police accountability can reduce police violence towards trans people and their disparate rates of arrest-especially when it comes to the profiling of trans communities (Stotzer 2014). Police and prison reform is a direct way to address the health needs of and violence affecting trans communities (see Reisner et al. 2014).

\section{Healthcare workers: learn about ways to provide supportive, affirming care to trans patients}

Research widely documents that healthcare workers (including psychotherapists) are often ill-equipped to treat trans patients, even frequently abusing them and/or committing microaggressions (Grant et al. 2011; James et al. 2016; Morris et al. 2020). Education and training (e.g., sponsoring workshops, engaging with resources created by trans people, hiring a trans person with experience in the medical or mental health industry to provide educational sessions) will be necessary to mitigate the abuse that trans people endure in healthcare settings. Importantly, Metzl and Hansen (2018) outline the utility of structural competency, a social justice framework for clinical practitioners that implores them to consider how social and political structures reinforce health inequalities and acknowledge that these structures shape their interactions with clients.

\section{Pharmaceutical companies and government bodies: take measures to increase vaccination rates and address medical mistrust within trans communities}

Halting the spread of COVID-19, especially with the emerging variants, requires an uptake in vaccination, suggesting that organizations must address the concerns of trans communities among other marginalized populations. Pharmaceutical companies can address trans people's vaccination concerns by including them appropriately in clinical trials, sharing trans-specific information on possible side effects and drug interactions in vaccine public service announcements, and employing trans people across all functions to support trans visibility, perspectives, and inclusion in their work. Similarly, government bodies can involve (trans) community leadership in vaccine outreach programs, especially in places where concentrated (and often the most marginalized) trans populations exist (e.g., prisons).

\section{Allies: express disapproval of transphobic policies and/or actions}

Among others, this can be done in the form of peaceful protesting, writing to/calling congresspeople, voting for politicians who support trans rights, creating and signing petitions, and writing policy briefs. Various trans-led activist organizations are leading this work as well (e.g., The Silvia Rivera Law Project), and financially supporting them can directly contribute to trans liberation. 


\section{Allies: perform respectful and effective allyship}

Allyship is an active process in which members of a dominant group work to mitigate oppression in their lives by supporting and advocating for a marginalized group (Washington and Evans 1991). Various scholars and activists have published insightful work around allyship, which can guide the actions of individuals aiming to support trans communities (e.g., Preston 2018). As cis authors, we aim to discuss statistics and objective facts about trans experiences (rather than telling "own voice" narratives), keeping in mind that a core piece of allyship is using one's privilege to uplift (Gallagher 2020) rather than speak over them. As it pertains to self-education, allies should engage with resources created by trans people and listen to trans people who are willing to share their experiences. Further, allies must work to educate those around them about trans issues and combat discrimination, prejudice, and biases in those people (see Sue et al. 2019 for helpful strategies). This comprehensive form of allyship can affirm and uplift trans communities by supporting their safety, identities, and collaboratively fighting for their rights in the present and the future.

\section{Conclusion}

As of August 2021, the COVID-19 crisis has caused well over 600,000 deaths in the U.S. alone (CDC 2020b), leaving many people feeling isolated, devastated, and fearful, even as vaccinations are widely distributed. While all people's lives have been affected in some way, examining the impact of the crisis is incomplete without considering privilege, marginalization, and power structures through an intersectional lens. Indeed, it is well documented that the effects of COVID-19, as other natural disasters and crises, have impacted marginalized Americans far more than those with more power and privilege. The U.S. government has failed to appropriately provide resources (e.g., federal financial aid, comprehensive universal health care) and dismantle the systems that endanger marginalized communities. In the present review, we outlined various factors, both individual-level and systems-level, that heighten trans communities' risk of exposure to COVID-19 and barriers to accessing affirming and safe healthcare (e.g., being refused care due to being trans; experiencing abuse from medical professionals; Grant et al. 2011). The factors we considered fall into two separate but deeply intertwined categories-health disparities and structural disparities. For instance, healthcare is pertinent to both physical and mental health, and is a form of structural, macrosystemic oppression; trans people use drugs and alcohol far more than their cis counterparts (Arayasirikul et al. 2018) which places them at a heightened risk of experiencing complications should they contract COVID-19 (CDC 2020a); and HIV status and mental health issues (e.g., schizophrenia, bipolar disorder) are closely linked (Rosenberg et al. 2001).

Guided by intersectionality and bioecological theories, we considered the complexity and diversity of trans identities and experiences, and examined multiple layers of context that oppress, invalidate, stigmatize, and endanger trans bodies. Further, we located multiple structural barriers to trans liberation. Naming violent power structures is integral to any and all liberation and intersectional work (Buchanan and 
Wiklund 2021). As such, it is necessary to acknowledge that transphobia is rooted in white supremacy and colonization, as trans people (and trans PoC in particular) threaten the cisheteropatriarchy established by White settlers. Colonization annihilated expansive conceptualizations of gender identities (e.g., Two-Spirit people; see Wilson 1996; Paramo 2018) and continues to strictly enforce a gender binary (Upadhyay 2021; Leo 2020) based on sex assigned at birth, punishing those who do not conform to it. U.S. colonial systems viewed Two-Spirit identities as a threat to their power, and "sequester[ed them]... away from their fundamental role in Indigenous life-worlds" (Leo 2020, p. 458). Indeed, dismantling transphobia inherently involves decoloniality, including leveraging the visions of people with expansive, nonbinary gender identities (Leo 2020). White supremacy, like transphobia, operates at multiple levels of context, from the microsystem to the macrosystem, contributing to its particularly insidious and lasting impacts.

Relatedly, a key limitation of this review is that a dearth of COVID-19 data accurately reflect trans identities. Public health data exist and operate in an exclusive, binary model of gender and "biological" sex, which is a mechanism of trans and/ or nonbinary erasure (Perret et al. 2021). While burgeoning work has used primary data to examine the experiences of trans people through the COVID-19 pandemic (e.g., Jarrett et al. 2020; Poteat et al. 2020), far more scholarship is warranted. It is vital that researchers center the perspectives of trans people who experience multiple marginalizations, as intersectional work can inform interventions and shape policy in ways that directly support trans communities (see Bowleg 2008). Finally, as cis scholars, we cannot personally speak to trans experiences or identities. Therefore, in addition to the outlined recommendations, it is vital that trans individuals' and communities' voices are elevated in conversations around their liberation.

When engaging in advocacy work and scholarship around transphobia and trans liberation, it is vital to explicitly appreciate and acknowledge the vibrance, resilience, and joy that exists within trans communities, pushing back on the deficitsoriented view that commonly shows up in queer literature and society at large. Trans communities deserve safety, validation, and care, and it is essential to honor their experiences, identities, and expertise.

Acknowledgements When the manuscript for this article was drafted, the first author self-identified as a U.S. White cisgender gay man and the second author self-identified as a cisgender queer South Asian woman. We thank Ira Chatterjee for insightful and detailed feedback on this manuscript.

Author contributions P. D. G. outlined the initial manuscript; P. D. G. and I. C. contributed to the review of the literature, development of the manuscript, and revision process.

\section{Declarations}

Conflict of interest P. D. Goldie declares that he has no conflict of interest. I. Chatterjee declares that she has no conflict of interest.

Research involving human and animals rights This article does not contain any studies with human participants or animals performed by any of the authors. 


\section{References}

Aggarwal NK, Consavage KE, Dhanuka I, Clement KW, Buoy JH (2021) Health and health care access barriers among Transgender women engaged in sex work: a synthesis of U.S.-based studies published 2005-2019. LGBT Health 8:11-25. https://doi.org/10.1089/lgbt.2019.0243

Almazan AN, Keuroghlian AS (2021) Association between gender-affirming surgeries and mental health outcomes. JAMA Surg 156:611-618. https://doi.org/10.1001/jamasurg.2021.0952

American Psychiatric Association (2013) Diagnostic and statistical manual of mental disorders, 5th edn. APA, Virginia

American Psychological Association (2020) How COVID-19 impacts sexual and gender minorities. Available via https://www.apa.org/topics/covid-19/sexual-gender-minorities. Accessed 31 Aug 2020

Andrasik MP, Yoon R, Mooney J, Broder G, Bolton M, Votto T, Davis-Vogel A (2014) Exploring barriers and facilitators to participation of male-to-female transgender persons in preventive HIV vaccine clinical trials. Prev Sci 15:268-276. https://doi.org/10.1007/s11121-013-0371-0

Arayasirikul S, Pomart W, Raymond H, Wilson E (2018) Unevenness in health at the intersection of gender and sexuality: sexual minority disparities in alcohol and drug use among transwomen in the San Francisco Bay Area. J Homosex 65:66-79. https://doi.org/10.1080/00918369.2017.1310552

Badgett MVL, Choi SK, Wilson BDM (2019) LGBT poverty in the United States: a study of differences between sexual orientation and gender identity groups. UCLA Williams Institute. Available via https://epgn.com/wp-content/uploads/2019/11/National-LGBT-Poverty-Oct-2019.pdf. Accessed 7 Jul 2021

Becker AB, Todd ME (2018) Watching the evolution of the American family? Amazon's transparent, ecological systems theory, and the changing dynamics of public opinion. J Homosex 32:1120-1137. https://doi.org/10.1080/00918369.2017.1406212

Bennet F, Molofsky A (2019) The immune system and psychiatric disease: a basic science perspective. Clin Exp Immunol 197:294-307. https://doi.org/10.1111/cei.13334

Bouman W, Claes L, Brewin N, Crawford J, Millet C, Fernandez-Aranda F, Arcelus J (2017) Transgender and anxiety: a comparative study between Transgender people and the general population. Int J Transgend 18:16-26. https://doi.org/10.1080/15532739.2016.1258352

Bowleg L (2008) When Black + Lesbian + Woman $\neq$ Black Lesbian Woman: the methodological challenges of qualitative and quantitative intersectionality research. Sex Roles 59:312-325. https://doi. org/10.1007/s11199-008-9400-z

Bronfenbrenner U (1977) Toward an experimental ecology of human development. Am Psychol 32:513531. https://doi.org/10.1037/0003-066X.32.7.513

Buchanan NT, Wiklund LO (2021) Intersectionality research in psychological science: resisting the tendency to disconnect, dilute, and depoliticize. Res Child Adolesc Psychopathol 49:25-31. https://doi. org/10.1007/s10802-020-00748-y

Bureau of Labor Statistics (2020) Fastest growing occupations. Available via https://www.bls.gov/emp/ graphics/2020/fastest-growing-occupations.htm. Accessed 16 Nov 2020

Carpenter LF, Marshall RB (2017) Walking while trans: profiling of transgender women by law enforcement and the problem of proof. Wm and Mary J Women and Law 24:5-38. Available via https:// scholarship.law.wm.edu/wmjowl/vol24/iss1/3. Accessed 9 Jul 2021

Carpenter CS, Eppink ST, Gonzales G (2020) Transgender status, gender identity, and socioeconomic outcomes in the United States. ILR Rev 73:573-599. https://doi.org/10.1177/0019793920902776

CDC (2020a) Alcohol and substance use. Available via https://www.cdc.gov/coronavirus/2019-ncov/ daily-life-coping/stress-coping/alcohol-use.html. Accessed 26 Aug 2020

CDC (2020b) Provisional death counts for coronavirus disease 2019 (COVID-19). Available via https:// www.cdc.gov/nchs/nvss/vsrr/covid19/index.htm. Accessed 31 Aug 2021

CDC (2020c) HIV surveillance report, 2018 (Updated); vol. 31. Available via http://www.cdc.gov/hiv/ library/reports/hiv-surveillance.html. Accessed 31 Aug 2020

CDC (2020d) If you are immunocompromised, protect yourself from COVID-19. Available via https:// www.cdc.gov/coronavirus/2019-ncov/need-extra-precautions/immunocompromised.html. Accessed 16 Nov 2020

CDC (2020e) People at increased risk. Available via https://www.cdc.gov/coronavirus/2019-ncov/needextra-precautions/index.html. Accessed 26 Aug 2020 
Chavis K, Degnan C (2017) Curbing excessive force: a primer on barriers to police accountability. J ACS Issue Br 11 Available via https://www.acslaw.org/wp-content/uploads/2017/04/Curbing_Excessive_ Force.pdf. Accessed 31 Aug 2020

Collins PH, Bilge S (2020) Intersectionality. John Wiley and Sons, Hoboken

Creamer M, Wang T, Babb S, Cullen K, Day H, Willis G, Jamal A, Neff L (2019) Tobacco product use and cessation indicators among adults - United States, 2018. Morb Mortal Wkly Rep 68:1013-1019. https://doi.org/10.15585/mmwr.mm6845a2

Crenshaw K (1991) Mapping the margins: intersectionality, identity politics and the violence against Women of color. Stanf Law Rev 43:1241-1299. https://doi.org/10.2307/1229039

da Silva DT, Biello K, Lin WY, Valente PK, Mayber K, Hightow-Weirdman L, Bauermeister JA (2021) COVID-19 vaccine acceptance among an online sample of sexual and gender minority men and transgender women. Vaccines 9:204-213. https://doi.org/10.3390/vaccines9030204

Eaton LA, Driffin DD, Kegler C, Smith H, Conway-Washington C, White D, Cherry C (2015) The role of stigma and medical mistrust in the routine health care engagement of black men who have sex with men. Am J Pub Health 105:e75-e82. https://doi.org/10.2105/AJPH.2014.302322

Equal Justice Initiative (2020) COVID-19's impact on people in prison. Available via https://eji.org/news/ covid-19s-impact-on-people-in-prison/. Accessed 26 Aug 2020

Finch WH, Hernández Finch ME (2020) Poverty and Covid-19: rates of incidence and deaths in the United States during the first 10 weeks of the pandemic. Front Sociol 5:47. https://doi.org/10.3389/ fsoc. 2020.00047

Gallagher A (2020) Why should trans people trust non-trans authors to lead the conversation about our identities? The Guardian. Available via https://www.theguardian.com/books/2020/oct/16/whyshould-trans-people-trust-non-trans-authors-to-lead-the-conversation-about-our-identities. Accessed 5 Jan 2021

Goldstein Z, Khan M, Reisman T, Safer JD (2019) Managing the risk of venous thromboembolism in transgender adults undergoing hormone therapy. J Blood Med 10:209-216. https://doi.org/10.2147/ JBM.S166780

Gonzales G, Henning-Smith C (2017) Barriers to care among transgender and gender nonconforming adults. Millbank Q 95:726-748. https://doi.org/10.1111/1468-0009.12297

Gonzales G, Loret de Mola E, Gavulic KA, McKay T, Purcell C (2020) Mental health needs among Lesbian, Gay, Bisexual, and Transgender college students during the COVID-19 pandemic. J Adolesc Health 67:645-648. https://doi.org/10.1016/j.jadohealth.2020.08.006

Grant J, Mottet L, Tanis J, Harrison J, Herman J, Keisling M (2011) Injustice at every turn: a report of the National Transgender Discrimination Survey. National Center for Transgender Equality and National Gay and Lesbian Task Force. Available via https://transequality.org/sites/default/files/docs/ resources/NTDS_Report.pdf. Accessed 26 Aug 2020

Gregory M (2021) Why it's harder for many Transgender people to access (and trust) COVID-19 vaccines. Discover Magazine. Available via https://www.discovermagazine.com/health/why-its-harderfor-many-transgender-people-to-access-and-trust-covid-19. Accessed 9 Jul 2021

Guan W, Ni Z, Hu Y, Liang W, Ou C, He J, Liu L, Shan H, Lei C, Hui DSC, Du B, Li L, Zeng G, Yuen K-Y, Chen R, Tang C, Wang T, Chen P, Xiang J, ...Zhong N, (2020) Clinical characteristics of coronavirus disease 2019 in China. N Engl J Med 382:1708-1720. https://doi.org/10.1056/NEJMo a2002032

Guthrie RV (1976) Even the rat was white: A historical view of psychology. Pearson, London

Herman JL, Brown TNT, Haas AP (2019) Suicide thoughts and attempts among transgender adults: findings from the 2015 U.S. Transgender Survey. UCLA Williams Institute. Available via https://willi amsinstitute.law.ucla.edu/wp-content/uploads/Suicidality-Transgender-Sep-2019.pdf. Accessed 9 Jul 2021

Hoffman MA, Kruczek T (2011) A bioecological model of mass trauma: individual, community, and societal effects. Couns Psychol 39:1087-1127. https://doi.org/10.1177/0011000010397932

Human Rights Campaign (2020) The lives and livelihoods of many in the LGBTQ community are at risk amidst COVID-19 crisis. Available via https://hrc-prod-requests.s3-us-west-2.amazonaws.com/files/ assets/resources/COVID19-IssueBrief-032020-FINAL.pdf?mtime=20200811115717\&focal=none. Accessed 7Jul 2021

Human Rights Campaign, PSB Research (2021) The economic impact of COVID-19 intensifies for transgender and LGBTQ communities of color. Available via https://assets2.hrc.org/files/assets/ resources/COVID19-EconImpact-Trans-POC-061520.pdf?_ga=2.55254831.563178050.16158 32550-1692325971.1604065274. Accessed 9 Jul 2021

\section{SN Social Sciences}

A SPRINGER NATURE journal 
Irvine A (2014) You can't run from the police: developing feminist criminology that incorporates Black transgender women. Sw L Rev 43:553-561

Jackson M, Holzman B (2020) A century of educational inequality in the United States. Proc Natl Acad Sci 117:19108-19115. https://doi.org/10.1073/pnas.1907258117

Jaiswal J, Halkitis PN (2019) Towards a more inclusive and dynamic understanding of medical mistrust informed by science. Behav Med 45:79-85. https://doi.org/10.1080/08964289.2019.1619511

James S, Herman JL, Rankin S, Keisling M, Mottet L, Anafi M (2016) Executive summary of the report of the 2015 U.S. transgender survey. Washington, DC: National Center for Transgender Equality. Available via https://transequality.org/sites/default/files/docs/usts/USTS-Full-Report-Dec17.pdf. Accessed 26 Aug 2020

Jarrett B, Peitzmeier SM, Restar A, Adamson T, Howell S, Baral S, Beckham SW (2020) Genderaffirming care, mental health, and economic stability in the time of COVID-19: a global crosssectional study of transgender and non-binary people. medRxiv. https://doi.org/10.1101/2020.11. 02.20224709

Johns MM, Lowry R, Andrzejewski J, Barrios LC, Demissie Z, McManus T, Raspberry CN, Robin L, Underwood JM (2019) Transgender identity and experiences of violence victimization, substance use, suicide risk and sexual risk behaviors among high school students-19 states and large urban school districts, 2017. Morb Mortal Wkly Rep 68:67-71. https://doi.org/10.15585/ mmwr.mm6803a3

Kantamneni N (2020) The impact of the COVID-19 pandemic on marginalized populations in the United States: a research agenda. J Vocat Behav 119:103439. https://doi.org/10.1016/j.jvb.2020. 103439

Klein A, Golub SA (2016) Family rejection as a predictor of suicide attempts and substance misuse among transgender and gender noncomforming adults. LGBT Health 3:193-199. https://doi.org/ 10.1089/lgbt.2015.0111

Kochhar R, Cilluffo A (2018) Income inequality in the U.S. is rising most rapidly among Asians. Pew Research Center. Available via http://www.pewsocialtrends.org/2018/07/12/income-inequalityin-the-u-s-is-rising-most-rapidly-among-asians/. Accessed 31 Aug 2020

Kofman A, Kantor R, Adashi EY (2021) Potential COVID-19 endgame scenarios: eradication, elimination, cohabitation, or conflagration? JAMA 326:303-304. https://doi.org/10.1001/jama.2021. 11042

Kosciw J, Greytak E, Palmer N, Boesen M (2014) The 2013 National School Climate Survey. Available via https://www.glsen.org/sites/default/files/2020-03/GLSEN-2013-National-School-Climate-Survey-Full-Report.pdf. Accessed 7 Jul 2021

Lambda Legal (2015) Protected and served? The executive summary of Lambda Legal's national survey that explores discrimination by police, courts, prisons and school security against lesbian, gay, bisexual, transgender (LGBT) people and people living with HIV in the United States. Available via https://www.lambdalegal.org/sites/default/files/publications/downloads/ps_executive-summary.pdf. Accessed 7 Jul 2021

Legal Services NYC (2016) Poverty is an LGBT issue: an assessment of the legal needs of low income LGBT people. Author. Available via https://lgbtqbar.org/annual/wp-content/uploads/sites/7/2016/ 06/3-Protected-and-Served-21-83.pdf. Accessed 31 Aug 2021

Leo B (2020) The colonial/modern [cis] gender system and trans world traveling. Hypatia 35:454-474. https://doi.org/10.1017/hyp.2020.27

Leppel K (2016) The labor force status of transgender men and women. Int J Transgend 17:155-164. https://doi.org/10.1080/15532739.2016.1236312

Massachusetts Department of Public Health (2009) The health of Lesbian, Gay, Bisexual, and Transgender (LGBT) persons in Massachusetts. Available via https://www.masstpc.org/wp-content/uploads/ 2012/10/DPH-2009-lgbt-health-report.pdf. Accessed 26 Aug 2020

May V (2015) Pursuing intersectionality, unsettling dominant imaginaries. Routledge, New York

Metzl JM, Hansen H (2018) Structural competency and psychiatry. JAMA Psychiat 75(115):116. https:// doi.org/10.1001/jamapsychiatry.2017.3891

Meyer I (2003) Prejudice, social stress, and mental health in lesbian, gay, and bisexual populations: conceptual issues and research evidence. Psychol Bull 129:674-697. https://doi.org/10.1037/00332909.129.5.674

Morris ER, Lindley L, Galupo MP (2020) "Better issues to focus on": transgender microaggressions as ethical violations in therapy. Couns Psychol 48:883-915. https://doi.org/10.1177/0011000020 924391 
Nagata J, Murray S, Compte E, Pak E, Schauer R, Flentje A, Capriotti MR, Lubensky ME, Lunn MR, Obedin-Maliver J (2020) Community norms for the eating disorder examination questionnaire (EDE-Q) among transgender men and women. Eat Behav 37:101381. https://doi.org/10.1016/j.eatbeh.2020.101381

Newberry L (2020) A crisis hotline for transgender people, by transgender people. Los Angeles Times. Available via https:/www.latimes.com/california/story/2020-09-07/a-crisis-hotline-for-transgenderpeople-by-transgender-people. Accessed 7 Jul 2021

O'Reilly M (2020) Systems centered language: speaking truth to power during COVID-19 while confronting racism. Medium. Available via https://meagoreillyphd.medium.com/systems-centeredlanguage-a3dc7951570e. Accessed 31 August 2021

Paramo M (2018) Transphobia is a white supremacist legacy of colonialism. Medium. Available via https://medium.com/@Michael_Paramo/transphobia-is-a-white-supremacist-legacy-of-colonialisme50f57240650. Accessed 7 July 2021

Perez-Brumer A, Silva-Santisteban A (2020) COVID-19 policies can perpetuate violence against transgender communities: insights from Peru. AIDS Behav 24:2477-2479. https://doi.org/10.1007/ s10461-020-02889-Z

Perret M, Jillson K, Danielsen AC, Trinh M-H, Zubizarreta D, DuBois LZ (2021) COVID-19 data on Trans and Gender-expansive people, stat! Health Aff Blog. https://doi.org/10.1377/hblog20210510. 756668

Peters JJ, Peers JH, Olansky S, Cutler JC, Gleeson GA (1955) Untreated syphilis in the male Negro; pathologic findings in syphilitic and nonsyphilitic patients. J Chronic Dis 1:127-148. https://doi.org/ 10.1016/0021-9681(55)90204-6

Pew Research Center (2016) Where the public stands on religious liberty vs. nondiscrimination. Available via https://www.pewforum.org/2016/09/28/where-the-public-stands-on-religious-liberty-vsnondiscrimination/. Accessed 31 Aug 2020

Poteat T, Reisner S, Miller M, Wirtz A (2020) COVID-19 vulnerability of Transgender women with and without HIV infection in the Eastern and Southern U.S. J Acquir Immune Defic Syndr 85(4):e67e69. https://doi.org/10.1097/QAI.0000000000002490

Preston AM (2018) Effective allyship: a Transgender woman's take on intersectionality. TedTalk. Available via https://www.ted.com/talks/ashlee_marie_preston_effective_allyship_a_transgender_ woman_s_take_on_intersectionality_jan_2018. Accessed 7 Jul 2021

Reisner SL, Bailey Z, Sevelius J (2014) Racial/ethnic disparities in history of incarceration, experiences of victimization, and associated health indicators among Transgender women in the U.S. Women Health 54:750-767. https://doi.org/10.1080/03630242.2014.932891

Rosenberg S, Goodman L, Osher F, Swartz MS, Essock SM, Butterfield MI, Constantine NT, Wolford GL, Salyers MP (2001) Prevalence of HIV, hepatitis B and hepatitis C in people with severe mental illness. Am J Pub Health 91:31-37. https://doi.org/10.2105/ajph.91.1.31

Safer JD, Coleman E, Feldman J, Garofalo R, Hembree W, Radix A, Sevelius J (2016) Barriers to healthcare for transgender individuals. Curr Opin Endocrinol Diabetes Obes 23:168-171. https://doi.org/ 10.1097/MED.0000000000000227

Saloner B, Parish K, Ward J, DiLaura G, Dolovich S (2020) COVID-19 cases and deaths in federal and state prisons. J Am Med Assoc 324:602-603. https://doi.org/10.1001/jama.2020.12528

Sawyer W, Wagner P (2020) Mass incarceration: the whole pie 2020. Prison Policy Initiative. Available via https://www.prisonpolicy.org/reports/pie2020.html. Accessed 26 Aug 2020

Sears B, Conron KJ, Flores AR (2021) The impact of the Fall 2020 COVID-19 surge on LGBT adults in the US. UCLA Williams Institute. Available via https://williamsinstitute.law.ucla.edu/wp-content/ uploads/COVID-LGBT-Fall-Surge-Feb-2021.pdf. Accessed 6 Jul 2021

Shelton C (2020) Feeling the pressures of the pandemic: suicide hotlines see 800 percent spike in calls. Fox News. Available via https://fox17.com/news/local/feeling-the-pressures-of-the-pandemic-suici de-hotlines-see-800-percent-spike-in-calls. Accessed 26 Aug 2020

Simmons K (2015) Increasing police accountability: restoring trust and legitimacy through the appointment of independent prosecutors. Wash Univ J Law Policy 49:137-158. Available via https://opens cholarship.wustl.edu/law_journal_law_policy/vol49/iss1/11. Accessed 17 Nov 2020

Stotzer RL (2014) Law enforcement and criminal justice personnel interactions with transgender people in the United States: a literature review. Aggress Viol Behav 19:263-277. https://doi.org/10.1016/j. avb.2014.04.012 
Sue DW, Alsaidi S, Awad MN, Glaeser E, Calle CZ, Mendez N (2019) Disarming racial microaggressions: microintervention strategies for targets, White allies, and bystanders. Am Psychol 75:128142. https://doi.org/10.1037/amp0000296

United States Census Bureau (2020) Household pulse survey. Available via https://www.census.gov/ programs-surveys/household-pulse-survey/data.html. Accessed 26 Aug 2020

Upadhyay N (2021) Coloniality of White feminism and its transphobia: a comment on Burt. Fem Criminol. https://doi.org/10.1177/1557085121991337

US Department of Health and Human Services (2010) How tobacco smoke causes disease: the biology and behavioral basis for smoking-attributable disease. U.S. Department of Health and Human Services, Public Health Service, Office of the Surgeon General.

US Department of Justice (2001) Promoting police integrity: examples of promising police tactics and policies. Available via https://www.ojp.gov/pdffiles1/ojp/186189.pdf. Accessed 31 Aug 2020

van der Miesen AIR, Raaijmakers D, van de Grift TC (2020) "You have to wait a little longer": transgender (mental) health at risk as a consequence of deferring gender affirming treatments during COVID-19. Arch Sex Behav. https://doi.org/10.1007/s10508-020-01754-3

Wang J, Geng L (2019) Effects of socioeconomic status on physical and psychological health: lifestyle as a mediator. Int J Environ Res Public Health 16:281. https://doi.org/10.3390/ijerph16020281

Wang Q, Xu R, Volkow ND (2020) Increased risk of COVID-19 infection and mortality in people with mental disorders: analysis from electronic health records in the United States. World Psychiatry 20:124-130. https://doi.org/10.1002/wps.20806

Washington J, Evans N (1991) Becoming an ally. In: Evans NJ, Wall VA (eds), Beyond tolerance: gays, lesbians, and bisexuals on campus (pp. 195-204). Am Coll Pers Assoc.

Wesp LM, Malcoe LH, Elliott A, Poteat T (2019) Intersectionality research for Transgender health justice: a theory-driven conceptual framework for structural analysis of Transgender health inequities. Transgend Health 4:287-296. https://doi.org/10.1089/trgh.2019.0039

Wildra E, Hayre D (2020) Failing grades: states' responses to COVID-19 in jails and prisons. Prison Policy Initiative. Available via https://www.prisonpolicy.org/reports/failing_grades.html\#PPE. Accessed 31 Aug 2020

Wilson A (1996) How we find ourselves: identity development and two-spirit people. Harv Educ Rev 66:303-317. https://doi.org/10.17763/haer.66.2.n551658577h927h4

Witcomb G, Bouman WP, Claes L, Brewin N, Crawford J, Arcelus J (2018) Levels of depression in transgender people and its predictors: results of a large matched control study with transgender people accessing clinical services. J Affect Disord 235:308-315. https://doi.org/10.1016/j.jad.2018.02. 051

Yancy CW (2020) COVID-19 and African Americans. J Am Med Assoc 323:1891-1892. https://doi.org/ 10.1001/jama.2020.6548 